some made from Etruria marl, containing about 11 per cent iron oxide. The kiln temperature was $1150^{\circ} \mathrm{C}$. The content of iron oxide (mainly $\mathrm{Fe}_{2} \mathrm{O}_{3}$ ), to which such ferromagnetic properties may be attributed, varies considerably in the materials from which bricks are made. It is usually well below 2 per cent in the fire-clays giving white and cream bricks, about 7 per cent in the clays giving red bricks, and 10 per cent or more in those giving blue and black bricks. Among recent relevant investigations are those of Koenigsberger (Phys. Z., 33, 468; 1932) on hæmatite $\left(\mathrm{Fe}_{2} \mathrm{O}_{3}\right)$, magnetite $\left(\mathrm{Fe}_{3} \mathrm{O}_{4}\right)$ and other ferromagnetic compounds. He finds that hæmatite, when cooled down in the earth's vertical field $(0.4$ gauss) from above the Curie point (about $670^{\circ} \mathrm{C}$.), shows a residual magnetisation which approaches the saturation remanence, and may be a considerable fraction of the saturation magnetisation. It is, of course, not possible to generalise about bricks. Each set of bricks presents a special problem, and precise discussion of the magnetic properties would require a detailed knowledge of the chemical composition of the clays, and of the conditions of baking and cooling. It is, however, probably not widely realised that most bricks are magnets-though feeble ones; and Mr. Bocking's observations are of interest in indicating that the phenomenon of thermo-remanence may be demonstrated with such a common object as an ordinary brick.

\section{A Remarkable Cloud Form}

A PHotograph of a remarkable cloud, of which a reproduction is shown in Fig. 1, has been received from Prof. I. S. Astapowitsch, of the Astronomical Institute, Fontanka 34, Leningrad. It was observed some time in 1932 at Stalinabad (lat. $38^{\circ} 34^{\prime}$ N., long. $68^{\circ} 47^{\prime}$ E.) above the Hissar Valley, and is described as having a rotational movement. Rotation round a vertical axis is strongly suggested by the appearance in the photograph of the middle and upper parts of the cloud. Students of cloud.

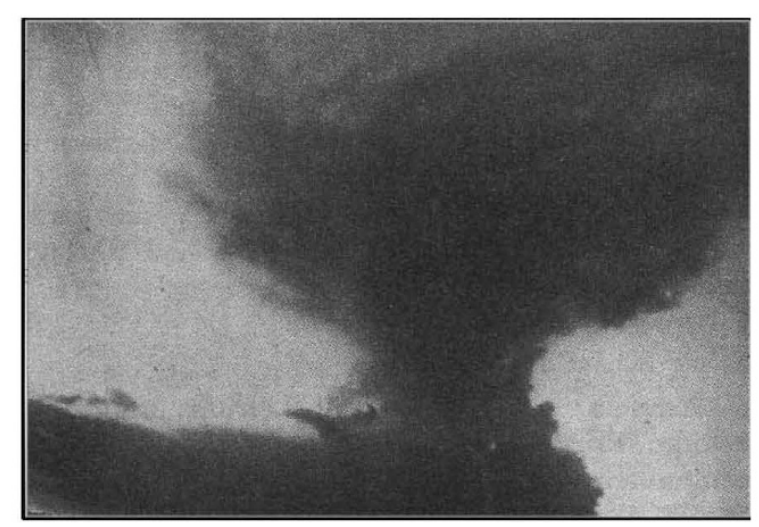

FIG. 1.

forms will recognise at once the very unusual character of this cloud, which has some structural resemblance both to the cumulo-nimbus cloud associated with a thunderstorm and to the funnel cloud of the tornado. By a curious coincidence, in a recent number of the Meteorological Magazine (Nov. 1934, vol. 69, No. 826) a sketch is shown of a cloud observed on October 4, 1934, near Waltham Cross, Hertfordshire, by Mr. Donald L. Champion, which has strong points of resemblance to the cloud just described. In each case a strong upward growth appears to have taken place over one part of a rather flattened cumulus cloud, the base of which was inclined to be convex, the central parts appearing to be lower than those farther from the centre. In the cloud near Waltham Cross the rapid vertical extension was formed in a few seconds, and after about five minutes the mushroom-shaped top spread out horizontally to form an 'anvil' cloud like those so often seen over thunder clouds. In both cases it is likely that opposed wind currents and convexion, perhaps associated with local heating, may have combined to produce rapid ascent of air with otation.

\section{Distribution of Birds at Sea}

Mos' ocean travellers must have noticed the very irregular distribution of birds on the open sea on different days, notwithstanding the apparently similar conditions of air and ocean. Censuses made during the crossing of the Atlantic record statistically these differences, but little attempt has been made to suggest a satisfactory reason for them. It seems very likely, however, that the presence or absence of pelagic birds is regulated by the oceanic currents, as S. C. Brooks suggests in the Condor (September 1934, p. 185). Oceanographers have shown that where the Arctic Current meets the North Atlantic Drift, there arise complexes of eddies and upwelling of the under waters, and that at the margin of contact there is a surface display of abundant organisms which attract fishes and other predators. This congregation of plenteous foodstuffs in limited areas may well attract pelagic birds, and Jesperson has already shown that there is a general connexion between the numbers of birds seen in a particular area at sea, and the quantity of macro-plankton in the surface waters. Pushing the probabilities further, it is likely that the migrations of oceanic birds may be related to the movements of plankton, by whatever determined, and tentatively Brooks makes the very interesting (but quite untested) suggestion that one of the factors which guided the homing terns of Bird Key from Cape Hatteras, to which they had been conveyed, back to the Tortugas, may have been the rich feeding grounds along the margin of the Gulf Stream. He adds that perhaps other factors too must be considered, such as the density of the air, which has been regarded as determining the northern limit of the distribution of the southern Atlantic wandering albatross.

\section{Flora of West Lancashire Dunes}

For some time, increasing concern has been felt amongst the botanists and Nature-lovers of this area for the dangerous position of the unique flora of the dunes of west Lancashire, particularly around Ainsdale. Recently two representatives of the Flora's League-a society for the preservation of wild flowers- 